\title{
Smokers with COPD Show a Shift in Energy and Nitrogen Metabolism at Rest and During Exercise
}

This article was published in the following Dove Press journal:

International Journal of Chronic Obstructive Pulmonary Disease

\author{
Olaf Holz $\mathbb{D}^{1, *}$ \\ David S DeLuca $\mathbb{1 D}^{2, *}$ \\ Stefan Roepcke ${ }^{3}$ \\ Thomas Illig ${ }^{2}$ \\ Klaus M Weinberger (iD) ${ }^{4-6}$ \\ Christian Schudt ${ }^{7}$ \\ Jens $M$ Hohlfeld (iD) ${ }^{1,2}$ \\ 'Fraunhofer ITEM, Biomedical Research \\ in Endstage and Obstructive Lung \\ Disease Hannover (BREATH), German \\ Center for Lung Research, Hannover, \\ Germany; ${ }^{2}$ Hannover Medical School, \\ Biomedical Research in Endstage and \\ Obstructive Lung Disease Hannover \\ (BREATH), German Center for Lung \\ Research, Hannover, Germany; \\ ${ }^{3}$ Department of Biomarker \\ Development, Takeda Pharmaceuticals \\ International $\mathrm{GmbH}$, Zürich, Switzerland; \\ ${ }^{4}$ Biocrates Life Sciences AG, Innsbruck, \\ Austria; ${ }^{5}$ Research Group for Clinical \\ Bioinformatics, Private University for \\ Health Sciences, Medical Informatics and \\ Technology, Hall in Tirol, Austria; \\ ${ }^{6}$ sAnalytiCo Ltd, Belfast, Ireland; \\ ${ }^{7}$ Department of Biochemistry, ALTANA, \\ Konstanz, Germany
}

*These authors contributed equally to this work
Correspondence: Olaf Holz

Department of Clinical Airway Research,

Fraunhofer ITEM, Hannover 30625,

Germany

Tel +49-5 I I-5350-8|4|

Fax +49-5II-5350-8250

Email olaf.holz@item.fraunhofer.de
Purpose: There is an ongoing demand for easily accessible biomarkers that reflect the physiological and pathophysiological mechanisms of COPD. To test if an exercise challenge could help to identify clinically relevant metabolic biomarkers in COPD.

Patients and Methods: We performed two constant-load exercise challenges separated by 4 weeks including smokers with COPD ( $n=23 / 19)$ and sex- and age-matched healthy smokers $(n=23 / 20)$. Two hours after a standardized meal venous blood samples were obtained before, 5 mins after the start, at the end of submaximal exercise, and following a recovery of 20 mins. Data analysis was performed using mixed- effects model, with the metabolite level as a function of disease, time point and interaction terms and using each individual's resting level as reference.

Results: Exercise duration was longer in healthy smokers but lactate levels were comparable between groups at all four time points. Glucose levels were increased in COPD. Glutamine was lower, while glutamate and arginine were higher in COPD. Branched-chain amino acids showed a stronger decline during exercise in healthy smokers. Carnitine and the acylcarnitines C16 and C18:1 were increased in COPD. These metabolite levels and changes were reproducible in the second challenge.

Conclusion: Higher serum glucose, evidence for impaired utilization of amino acids during exercise and a shift of energy metabolism to enhanced consumption of lipids could be early signs for a developing metabolic syndrome in COPD. In COPD patients, deviations of energy and nitrogen metabolism are amplified by an exercise challenge.

Keywords: targeted metabolomics, biomarker, airway inflammation

\section{Plain Language Summary}

There is an ongoing demand for easily accessible biomarkers to better understand, diagnose and treat chronic obstructive pulmonary disease (COPD). In this study, we tested, if metabolic blood biomarker signals can be enhanced by an exercise challenge. We performed two bicycle ergometer exercise challenges separated by 4 weeks with smokers that have COPD and healthy smokers. Both groups were comparable with respect to age and gender distribution. Following a standardized breakfast, we obtained blood samples before, 5 mins after the start, at the end of exercise, and following a recovery of 20 mins. The data analysis was performed using adequate tests using each individual's resting level as reference. The healthy smokers were able to perform the exercise for a longer duration but blood lactate levels indicated that both groups reached a comparable level of exhaustion at all four time points. Glucose levels were increased in COPD and a number of metabolites involved in energy generation showed differences in smokers with COPD. These metabolite levels and changes were reproducible in the second challenge. The observed metabolic deviations could be early 
indicators for a developing metabolic syndrome in COPD that are amplified by an exercise challenge.

\section{Introduction}

Chronic obstructive pulmonary disease (COPD) is characterized by chronic airway and systemic inflammation, dyspnea, decreased exercise tolerance, cough, and mucus production. $^{1,2}$ Biomarkers that reflect inflammation or comorbidities in COPD are rare $^{3}$ and established markers tracking disease activity or progression are limited. ${ }^{4}$ It is known that blood fibrinogen, adiponectin, interleukin 6 (IL6), and C-reactive protein are increased ${ }^{1,5,6}$ and related to exercise tolerance, exacerbation rate, and mortality. ${ }^{2,7,8,9}$ Breathlessness and reduced exercise capacity lead to less physical activity, which worsens the disease by increasing systemic inflammation in COPD. ${ }^{10}$

Exercise challenge has been used to enhance potential biomarker signals in COPD. It leads to an earlier increase and a larger change of IL6 and tumor necrosis factor- $\alpha$ compared to healthy controls. ${ }^{11}$ Correspondingly serum IL6 increased significantly in healthy and in COPD smokers in our study. ${ }^{5}$ In addition, serum von-Willebrand factor increased and myeloperoxidase decreased during exercise.

Metabolomic data from COPD patients suggests various disturbances in plasma and muscle amino acids at rest. $^{12}$ Engelen and colleagues showed a reduction of most muscle amino acids after exercise ${ }^{13}$ and altered leucine metabolism in COPD patients. ${ }^{14}$ Using global untargeted serum profiling, Chen and coworkers found 23 differentially regulated metabolites in COPD smokers vs healthy smokers. ${ }^{15}$ Telenga et al reported higher levels of sphingolipids in the sputum of COPD smokers compared to healthy smokers. ${ }^{16}$

It was our primary aim to amplify potential metabolomic biomarker signals which are related to specific pathophysiological processes in COPD. We investigated smokers with moderate COPD and sex- and age-matched healthy smokers as controls. The targeted metabolomics analysis in serum was performed before, during, and after exercise. To determine the robustness of the findings, the challenge was performed on two occasions. The focus of the analysis reported here lies on energy metabolism, including available carbohydrates, amino acids, carnitines, citric acid cycle and urea cycle metabolites, and a limited number of biogenic amines. This study was part of a comprehensive exploratory biomarker study and data of inflammatory markers were previously published. ${ }^{5,17,18}$

\section{Materials and Methods}

\section{Subjects}

Twenty-three smokers with COPD and 23 healthy smokers were included (Table 1). Patients were free of exacerbations or acute infections for 4 weeks prior to study visits. Additional exclusion criteria were signs for hepatic (particularly liver cirrhosis (Child B and C)), renal (creatinine above $2 \mathrm{mg} / \mathrm{dL}$ ), gastrointestinal, haematological, endocrinological, metabolic, neurological, psychiatric, or cardiovascular disorders particularly arterial hyper- or hypotension, symptomatic coronary heart disease (i.e. angina pectoris induced by stress or physical effort), congestive heart failure NYHA III and IV, and cardiac arrhythmia. The study was conducted in accordance with Good Clinical Practice and the Declaration of Helsinki and approved by the Hannover Medical School Ethical Committee. Subjects gave their written informed consent.

\section{Study Design}

Visits 1 and 2 (separated by 3-7 days) were followed 28 \pm 5 days later by visits 3 and 4 (separated by 3-7 days). The exercise challenges were performed at visits 1 and 3 two hours after a standardized breakfast (Figure 1). Forty-one subjects also participated in the second exercise challenge.

Table I Demographic and Physiological Parameters. For More Information Refer to. ${ }^{5}$

\begin{tabular}{|c|c|c|c|}
\hline & & $\begin{array}{l}\text { Healthy Smokers } \\
n=23\end{array}$ & $\begin{array}{l}\text { COPD Smokers } \\
n=23\end{array}$ \\
\hline Female/male & $\mathrm{n}$ & $6 / 17$ & $6 / 17$ \\
\hline Age & Years & $54(42,65)$ & $55(46,68)$ \\
\hline $\mathrm{BMI}$ & $\mathrm{kg} / \mathrm{m}^{2}$ & $25.4 \pm 2.5$ & $25.2 \pm 3,4$ \\
\hline Pack-years & & $39 \pm 23.2$ & $47.9 \pm 11.0 * * *$ \\
\hline $\mathrm{FEV}_{1}{ }^{\mathrm{a}}$ & L & $3.8 \pm 0.8$ & $2.2 \pm 0.4^{* * *}$ \\
\hline $\mathrm{FEV}_{1}{ }^{\mathrm{a}}$ & $\%$ pred & $112.5 \pm 14.1$ & $66.1 \pm 7.2^{* * *}$ \\
\hline $\mathrm{FEV}_{1} / \mathrm{FVC}^{\mathrm{a}}$ & $\%$ & $75.4 \pm 5.0$ & $50.0 \pm 8.7^{* * *}$ \\
\hline Systolic BP & {$[\mathrm{mmHg}]$} & $135.7 \pm 10.8$ & $133.4 \pm 17.7$ \\
\hline Diastolic BP & {$[\mathrm{mmHg}]$} & $83.2 \pm 8.8$ & $80.3 \pm 9.1$ \\
\hline WPeak & W & $154.8 \pm 35.1$ & $110.9 \pm 23.9 * * *$ \\
\hline
\end{tabular}

Notes: Values are presented as mean $\pm \mathrm{SD}$, age as median $(\min , \max ) . *^{*} *_{p}<0.001$, WPeak, Peak exercise level, which could be maintained for $30 \mathrm{~s}$ (during an escalation scheme with a stepwise increase in the work rate by $10 \mathrm{~W}$ every minute). ${ }^{a}$ Data of COPD patients were assessed post-bronchodilator treatment. Abbreviations: BMI, body mass index; BP, blood pressure. 


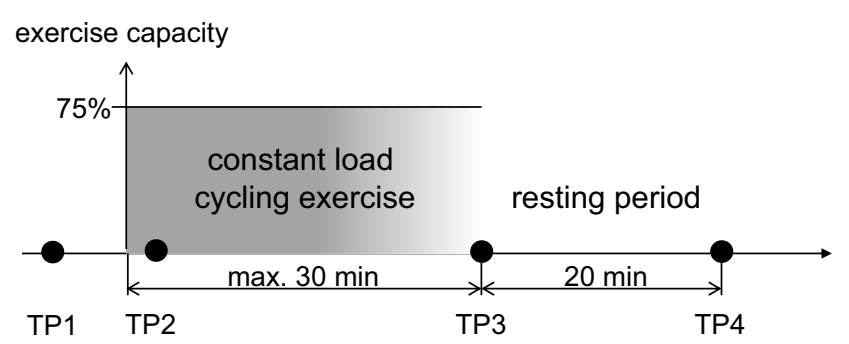

Figure I Study design. Time point (TP) I and TP2 (5 mins after the start of exercise) were fixed, while constant-load exercise was performed until the subject was exhausted; TP3 was therefore different between individuals (maximum duration 30 mins). The period of rest was always 20 mins following the end of the exercise.

Abbreviations: TP, time point; mins, minutes.

\section{Cycling Exercise}

Peak work capacity (Wpeak) was determined using a stepwise increase in the work rate by 10 Watts/minute with a pedaling rate within $50-70 \mathrm{rpm} .{ }^{19}$ The maximum work rate maintained for at least $30 \mathrm{~s}$ was defined as Wpeak. For the constant-load exercise challenge, the work rate was set to $75 \%$ of Wpeak (Table 1). Subjects were encouraged to exercise for $30 \mathrm{mins}$, but were allowed to discontinue if exhausted or symptoms occurred. We monitored blood oxygenation during exercise by pulse oximetry.

\section{Blood Analysis}

Venous blood was collected before exercise, after 5 mins of exercise, at the end, and 20 mins after exercise (Figure 1). The metabolite panel was analyzed using electrospray ionization tandem mass spectrometry ${ }^{20}$ (Biocrates Life Science AG, Austria ${ }^{21}$ ).

\section{Data Analysis}

To discover COPD-dependent and exercise-dependent effects and evaluate their significance mixed-effects models of the following form were employed.

$y_{m i t}=\alpha_{0 m(i \times v)}+\beta_{1 m} c_{i}+\beta_{2 m} t+\beta_{3 m} s_{i}+\beta_{4 m}\left(c_{i} \times t\right)+\varepsilon_{m i}$.

The measured quantity $y$ for a given metabolite $m$, individual $\mathrm{i}$, and time point $\mathrm{t}$ was modeled as a function of the fixed effects health status $\left(c_{i}\right.$, i.e. COPD vs control), time point, sex $\left(s_{i}\right)$ and an interaction term for $c_{i}$ and t. The effect of individual and visit were captured as a random intercept: $\alpha_{0 m(i \times v)}$. These models were implemented in R (lme4, lmerTest). Metabolites significantly affected by health status were identified through the use of an ANOVA with the null model (which included intercept, gender and time point, but excluded health status). Multiple hypothesis correction was applied using Benjamini Hochberg FDR. ${ }^{22}$ For specific terms in the model, nominal p-values are reported (Table 2).

Metabolite levels shown in the figures are based on the mean values from both visits of all subjects. If significant gender differences existed, genders are displayed separately. We did not consider the differences in exercise duration in the figures, but tested each metabolite in this respect and indicated correlations in the results. The reproducibility between visits was assessed by further applying the model separately for each visit.

\section{Results}

Groups were matched with respect to gender, age, and smoking behavior. We found no significant differences in urine cotinine. ${ }^{5}$ COPD patients showed a lower lung function and peak exercise capacity (Table 1). Information on serum and sputum inflammatory markers has been previously published. ${ }^{5,17}$ The median (IQR) exercise time of COPD smokers was 10.0 (4.0) minutes in the first and 10.0 (8.0) minutes in the second challenge. Healthy smokers exercised for a period of 22.0 (16.0) and 26.5 (14.5) minutes, respectively. Lactate levels did not differ between groups (Figure 2).

Energy metabolism was significantly affected by the time course of exercise. Thirty-one metabolites were affected by disease status, nine of which were only different at baseline. We assessed the reproducibility of the exercise challenge across metabolites by producing separate models for the first and second challenge and then plotting the effect sizes from the first challenge against those from the second (Figure 3). We observed a very high level of correlation, especially for those metabolites that showed significant effects.

Glucose was elevated in COPD and decreased with exercise in both groups. After exercise, healthy individuals exhibited a robust recovery of glucose, in contrast to COPD patients (Figure 2). Lactate increased 3 to 4 fold during exercise and decreased during rest with no significant differences between groups (Figure 2). Pyruvate exhibited this same pattern, and also succinate increased with exercise; however, its peak level was significantly higher in healthy smokers (Figure 4). Alpha-ketoglutaric acid ( $\alpha$-KGA) significantly increased with exercise, but without a corresponding drop during recovery. There was no effect of health status on $\alpha$-KGA but healthy individuals had a more pronounced increase that persisted during the recovery phase (Figure 4). 
Table 2 Mixed Model Results Based on Normalized Data Using the Method Described in data Analysis. For More Detailed Information Refer to Table EI

\begin{tabular}{|c|c|c|c|c|c|c|c|c|c|}
\hline \multirow[t]{2}{*}{$\begin{array}{l}\text { Significance Level } \\
\text { Indicates }\end{array}$} & Health Status & $\begin{array}{l}\text { Health } \\
\text { Status/ } \\
\text { TP2 }\end{array}$ & $\begin{array}{l}\text { Health } \\
\text { Status/ } \\
\text { TP3 }\end{array}$ & $\begin{array}{l}\text { Health } \\
\text { Status/ } \\
\text { TP4 }\end{array}$ & $\begin{array}{l}\text { FDR for Health } \\
\text { Status Effect }\end{array}$ & Gender & TP2 & TP3 & TP4 \\
\hline & $\begin{array}{l}\text { Difference } \\
\text { Between } \\
\text { Groups }\end{array}$ & \multicolumn{3}{|c|}{$\begin{array}{l}\text { Difference Between Groups in the } \\
\text { Response to Exercise Relative to } \\
\text { Difference Observed Before } \\
\text { Exercise }\end{array}$} & & $\begin{array}{l}\text { Gender } \\
\text { Difference }\end{array}$ & \multicolumn{3}{|c|}{$\begin{array}{l}\text { Difference } \\
\text { Between the } \\
\text { Level at the } \\
\text { Respective Time } \\
\text { Point Relative to } \\
\text { Baseline Level } \\
\text { (TPI, Before } \\
\text { Exercise) }\end{array}$} \\
\hline $\begin{array}{l}\text { Lactate } \\
\text { Pyruvate } \\
\text { Succinate } \\
\alpha-K G\end{array}$ & & & $\begin{array}{l}* * * \\
* * *\end{array}$ & $* *$ & $\begin{array}{l}* * * \\
* *\end{array}$ & $\begin{array}{l}* \\
*\end{array}$ & $\begin{array}{l}* * * \\
* * * \\
* * * \\
*\end{array}$ & $\begin{array}{l}* * * \\
* * * \\
* * * \\
* * *\end{array}$ & $\begin{array}{l}* * * \\
* * * \\
* \\
* * *\end{array}$ \\
\hline Hexose $^{a}$ & $* * *$ & & & $* * *$ & $* * *$ & & & $* *$ & $* * *$ \\
\hline $\begin{array}{l}\text { Acylcarnitines C0 } \\
\text { Acylcarnitines C2 } \\
\text { Acylcarnitines C3 } \\
\text { Acylcarnitines C4 } \\
\text { Acylcarnitines C16 } \\
\text { Acylcarnitines CI8:I } \\
\text { Total acylcamitines }\end{array}$ & $\begin{array}{l}* * * \\
\\
\\
* \\
* *\end{array}$ & & $\begin{array}{l}* \\
* \\
\sim \\
*\end{array}$ & $\begin{array}{l}* * \\
\\
\\
\sim \\
* *\end{array}$ & $\begin{array}{l}* * \\
* * \\
\\
* \\
* *\end{array}$ & $\begin{array}{l}* * * \\
* * \\
* * \\
* * * \\
* * * \\
* * *\end{array}$ & & $\begin{array}{l}* * * \\
* \\
* * *\end{array}$ & $\begin{array}{l}* * \\
* * * \\
\\
\sim \\
* * \\
* * *\end{array}$ \\
\hline $\begin{array}{l}\text { Total amino acids } \\
\text { Alanine ALA } \\
\text { Arginine ARG } \\
\text { Asparagine ASN } \\
\text { Citrulline CIT } \\
\text { Glutamine GLN } \\
\text { Glycine GLY } \\
\text { Histidine HIS } \\
\text { Isoleucine ILE } \\
\text { Leucine LEU } \\
\text { Lysine LYS } \\
\text { Methionine MET } \\
\text { Omithine ORN } \\
\text { Phenylalanine PHE } \\
\text { Proline PRO } \\
\text { Serine SER } \\
\text { Threonine THR } \\
\text { Tryptophan TRP } \\
\text { Tyrosine TYR } \\
\text { Valine VAL } \\
\text { Aspartate ASP } \\
\text { Glutamate GLU }\end{array}$ & $\begin{array}{l}* * \\
\sim \\
* \\
* \\
\sim \\
* \\
*\end{array}$ & & $\begin{array}{l}* * \\
* \\
* \\
* * \\
* * \\
* * \\
* * \\
* *\end{array}$ & $*$ & $\begin{array}{l}* * \\
* *\end{array}$ & $\begin{array}{l}* \\
* \\
\sim \\
* * * \\
* * * \\
* \\
\sim \\
* \\
* * * \\
* \\
\sim\end{array}$ & $\begin{array}{l}* * * \\
\\
* \\
* \\
\sim \\
*\end{array}$ & $\begin{array}{l}* \\
* * * \\
* * \\
* * * \\
*\end{array}$ & $\begin{array}{l}* * * \\
* * * \\
* * \\
* * * \\
* * \\
* * * \\
* * * \\
* * * \\
* * * \\
* * * \\
* * * \\
* * * \\
* * * \\
* * \\
* * * \\
* * * \\
* * * \\
* * * \\
* * * \\
* * * \\
*\end{array}$ \\
\hline $\begin{array}{l}\text { BCAA (LEU ILE VAL) } \\
\text { CIT/ARG } \\
\text { CIT/ORN }\end{array}$ & * & & $\begin{array}{l}* \\
* \\
* *\end{array}$ & $*$ & $\begin{array}{l}* * \\
* \\
*\end{array}$ & $* * *$ & & $\begin{array}{l}* \\
*\end{array}$ & $\begin{array}{l}* * * \\
* * * \\
* * *\end{array}$ \\
\hline
\end{tabular}

(Continued) 
Table 2 (Continued).

\begin{tabular}{|c|c|c|c|c|c|c|c|c|c|}
\hline \multirow[t]{2}{*}{$\begin{array}{l}\text { Significance Level } \\
\text { Indicates }\end{array}$} & Health Status & $\begin{array}{l}\text { Health } \\
\text { Status/ } \\
\text { TP2 }\end{array}$ & $\begin{array}{l}\text { Health } \\
\text { Status/ } \\
\text { TP3 }\end{array}$ & $\begin{array}{l}\text { Health } \\
\text { Status/ } \\
\text { TP4 }\end{array}$ & $\begin{array}{l}\text { FDR for Health } \\
\text { Status Effect }\end{array}$ & Gender & TP2 & TP3 & TP4 \\
\hline & $\begin{array}{l}\text { Difference } \\
\text { Between } \\
\text { Groups }\end{array}$ & \multicolumn{3}{|c|}{$\begin{array}{l}\text { Difference Between Groups in the } \\
\text { Response to Exercise Relative to } \\
\text { Difference Observed Before } \\
\text { Exercise }\end{array}$} & & $\begin{array}{l}\text { Gender } \\
\text { Difference }\end{array}$ & \multicolumn{3}{|c|}{$\begin{array}{l}\text { Difference } \\
\text { Between the } \\
\text { Level at the } \\
\text { Respective Time } \\
\text { Point Relative to } \\
\text { Baseline Level } \\
\text { (TPI, Before } \\
\text { Exercise) }\end{array}$} \\
\hline $\begin{array}{l}\text { Creatinine } \\
\text { Spermidine }\end{array}$ & $*$ & & & $*$ & $*$ & $* * *$ & $\begin{array}{l}\sim \\
* * *\end{array}$ & * & \\
\hline $\begin{array}{l}\text { Kynurenine } \\
\text { Serotonin (5-HT) } \\
\text { 5-HT/TRP } \\
\text { Kynurenine/TRP }\end{array}$ & $\sim$ & & $*$ & & & $\begin{array}{l}* * \\
* * *\end{array}$ & $\sim$ & $\begin{array}{l}* * \\
\sim \\
* \\
* * *\end{array}$ & $\begin{array}{l}\sim \\
* * * \\
* *\end{array}$ \\
\hline
\end{tabular}

Notes: ${ }^{a}$ Sum of hexose, widely represented by glucose: 90-95\%. : $p<0.1$ (trend), *: $p<0.05, * *$ : $p<0.01, * * *: p<0.001$.

Abbreviations: BCAA, branched-chain amino acids; $\alpha-K G$, alpha-ketoglutarate; TP, time point; FDR, false discovery rate; health status: healthy smoker or COPD smoker.

Total amino acids increased slightly with exercise and dropped to the lowest levels during the recovery phase. There was no effect of health status or gender. The recovery phase decline was observed for all amino acids with the exceptions of citrulline (CIT) and glutamic acid (GLU), which increased during recovery (Figure 2). The most significant disease effect was observed for arginine (ARG), which was elevated in COPD, along with GLU (Figure 2). Glutamine (GLN), histidine (HIS), leucine (LEU), serine (SER), and valine (VAL) showed generally higher levels in healthy smokers.

The effect of exercise was dependent on health status for several amino acids (Table 2). At the end of exercise alanine (ALA) and CIT increased at a greater rate in healthy individuals. Conversely, there was a more pronounced decrease in healthy individuals for isoleucine (ILE), LEU, methionine (MET), ornithine (ORN), phenylalanine (PHE), tryptophan (TRY), and tyrosine (TYR). The CIT/ARG ratios were initially similar between both groups, but the increases during exercise and the resting phase were more pronounced in the healthy controls (Figure 5). The CIT/ORN ratios also showed this pattern, however with higher levels in COPD patients.

Total acylcarnitines were comparable between groups at baseline. Their levels increased during exercise and resting in both groups, but more pronouncedly in healthy individuals. This pattern was also found for acylcarnitine C2 (Figure 5), the major acylcarnitine that correlated with the level of total acylcarnitines (Figure E1). Acylcarnintine C0, C16, and
C18:1 showed a slight decrease during rest. Carnitine (C0) was elevated in COPD over all time points (Figure 4).

Creatinine, kynurenine and spermidine increased with exercise (Figures 4 and 5), the latter was elevated in COPD.

\section{Discussion}

Serum metabolomic analysis revealed distinct and reproducible exercise-induced differences between smokers with and without COPD. COPD smokers showed signs for impaired energy generation with a shift to enhanced amino acids and free fatty acids utilization and a decreased metabolic flow through the tricarboxylic acid (TCA) cycle. Despite the absence of clinical signs for metabolic syndrome, our findings are compatible with characteristics expected early in the development of a metabolic syndrome. An attenuated NO generation in COPD could be among the potential reasons for deviations in nitrogen metabolism between groups.

\section{Caveats of Study Design}

COPD patients showed a shorter exercise duration despite a significantly lower workload, but as shown by serum lactate, pyruvate and ALA, we managed to induce a comparable metabolic burden in both groups. Our study differs from other metabolomic COPD studies, where either arterial blood $^{23}$ or arterialized venous blood ${ }^{13,14}$ was sampled after fasting periods. ${ }^{13,14,15,23,24}$ All our subjects were in the absorptive state after receiving a standardized meal to avoid clinical 

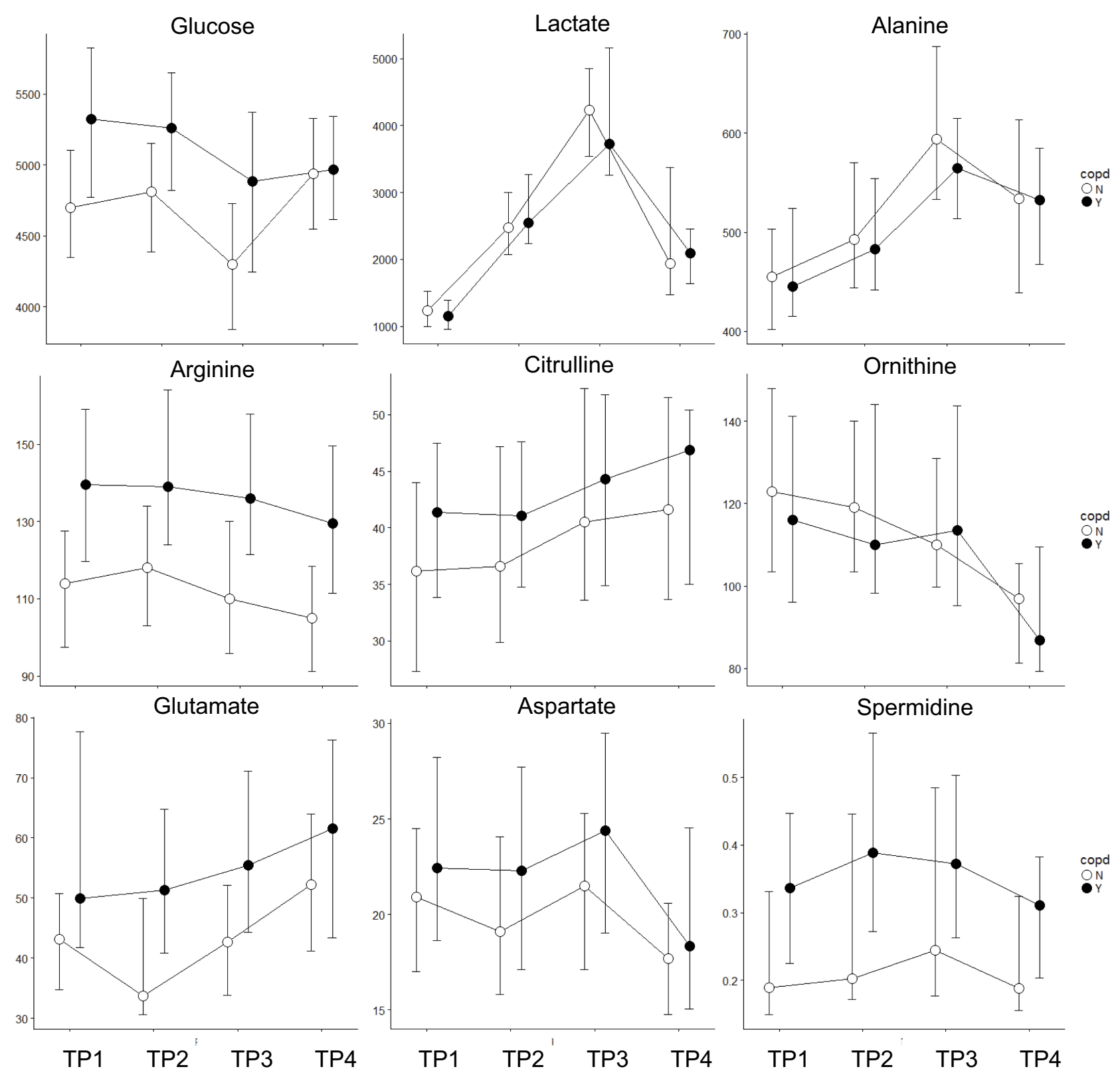

Figure 2 Metabolomic markers, which do not show a significant difference between genders separately for smokers with (black) and without (white) COPD. Median and IQR, including the data of both exercise challenges. Horizontal axis: the four time points, vertical axis: concentration in $\mu M$.

complications while exercising. We did not explicitly assess visceral obesity, insulin resistance, cholesterol or triglycerides to determine a clinical manifestation of a metabolic syndrome but the BMI and blood pressure values were similar in both groups and not beyond WHO defined thresholds.

\section{Exercise-Induced Metabolomics Patterns}

The metabolite patterns observed were compatible with the expected exercise-induced changes (Figure 5). Both groups showed a decline in glucose and very similar increases in lactate and pyruvate, products from glycolysis. ALA and creatinine produced and released by muscles during exercise showed the expected changes during exercise and recovery. The increase GLN, released from muscle during exercise, was not as pronounced, potentially due to consumption by gluconeogenesis in the kidneys. The enhanced production of energy by the TCA cycle is indicated by the patterns of succinate and $\alpha-\mathrm{KG}$. The exercise-induced increase of $\mathrm{C} 2$-acylcarnitine demonstrates that free fatty acids are converted to acetyl-CoA. ARG and spermidine indicate the effects of exercise on the removal of nitrogen through the urea cycle. The decline 


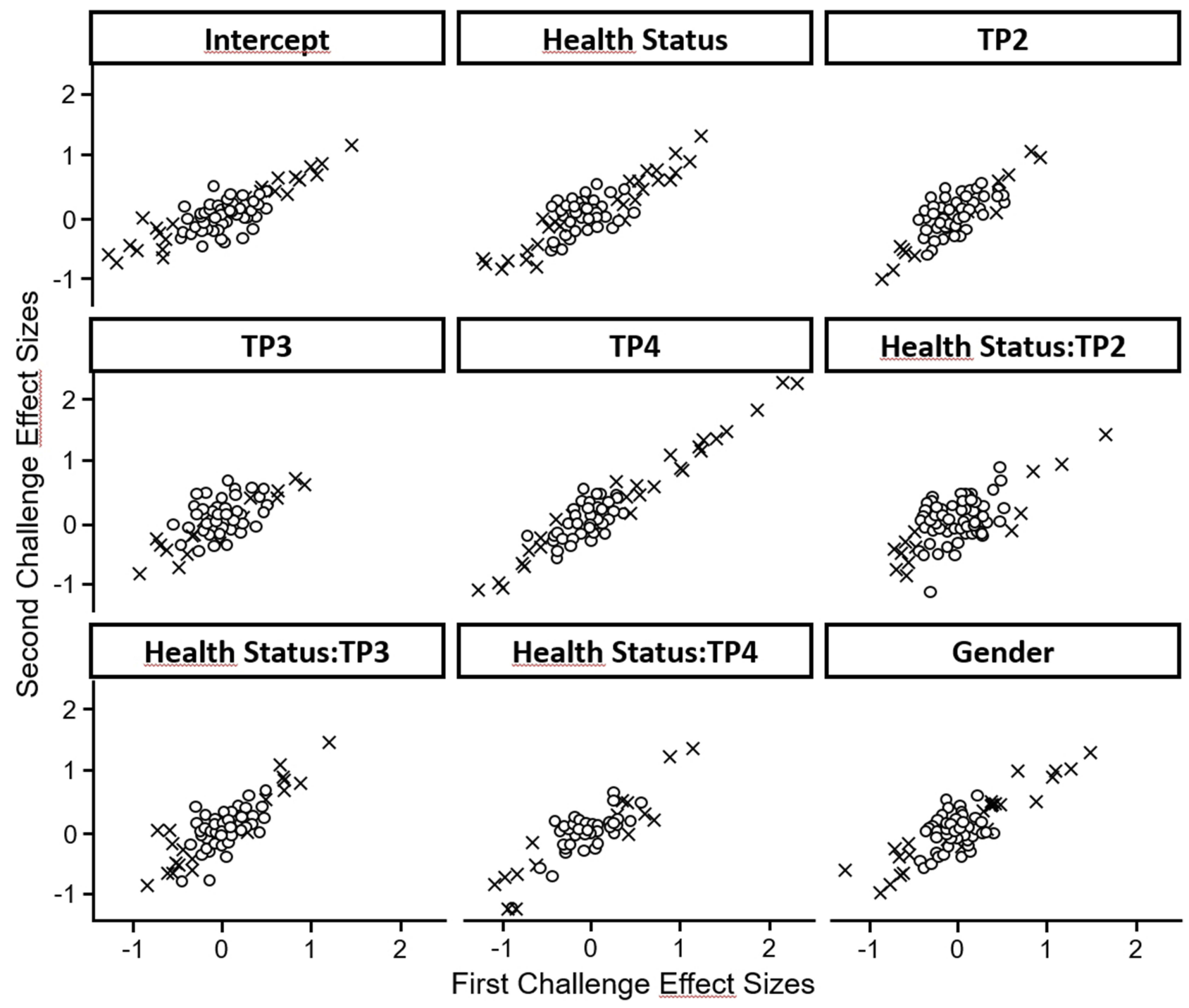

Figure 3 Correlation of effect sizes between the first and second exercise challenge. The figure shows that the effect sizes estimated in the mixed model correlate between the first and second exercise challenge. The correlation is better for markers showing a significant difference between groups. $x$ symbols: metabolites with significant effects $(p<0.05)$, open symbols: metabolites with non-significant effects.

Abbreviation: TP, time point.

for most amino acids levels during recovery is in line with increases in protein synthesis after exercise, ${ }^{25}$ or due to their utilization for gluconeogenesis.

The consistency of our results with expected exerciseinduced metabolic patterns is further supported by a number of correlations between metabolites at different time points (Figures E2-E5).

\section{Differences Between Smokers with and Without COPD}

\section{Carbohydrates at Rest and During Exercise}

Blood hexoses are widely (90-95\%) represented by glucose. ${ }^{26}$ While the mean glucose levels were in the normal range of $80-120 \mathrm{mg} / \mathrm{dL}(4.4-6.7 \mathrm{mM})$, the higher glucose in COPD smokers at rest and during exercise suggests that there is a limitation to utilize glucose as an energy source. The lower glucose increase during recovery in COPD was potentially due to limitations in processes that control and restore blood glucose resulting in a longer time period to restore the conditions observed during rest.

\section{Amino Acids at Rest}

The lower GLN and BCAA (LEU, VAL) levels at rest in COPD suggest a shift in energy metabolism from carbohydrates to amino acids and a stronger utilization of GLN, the most abundant and one of the major glucogenic amino 

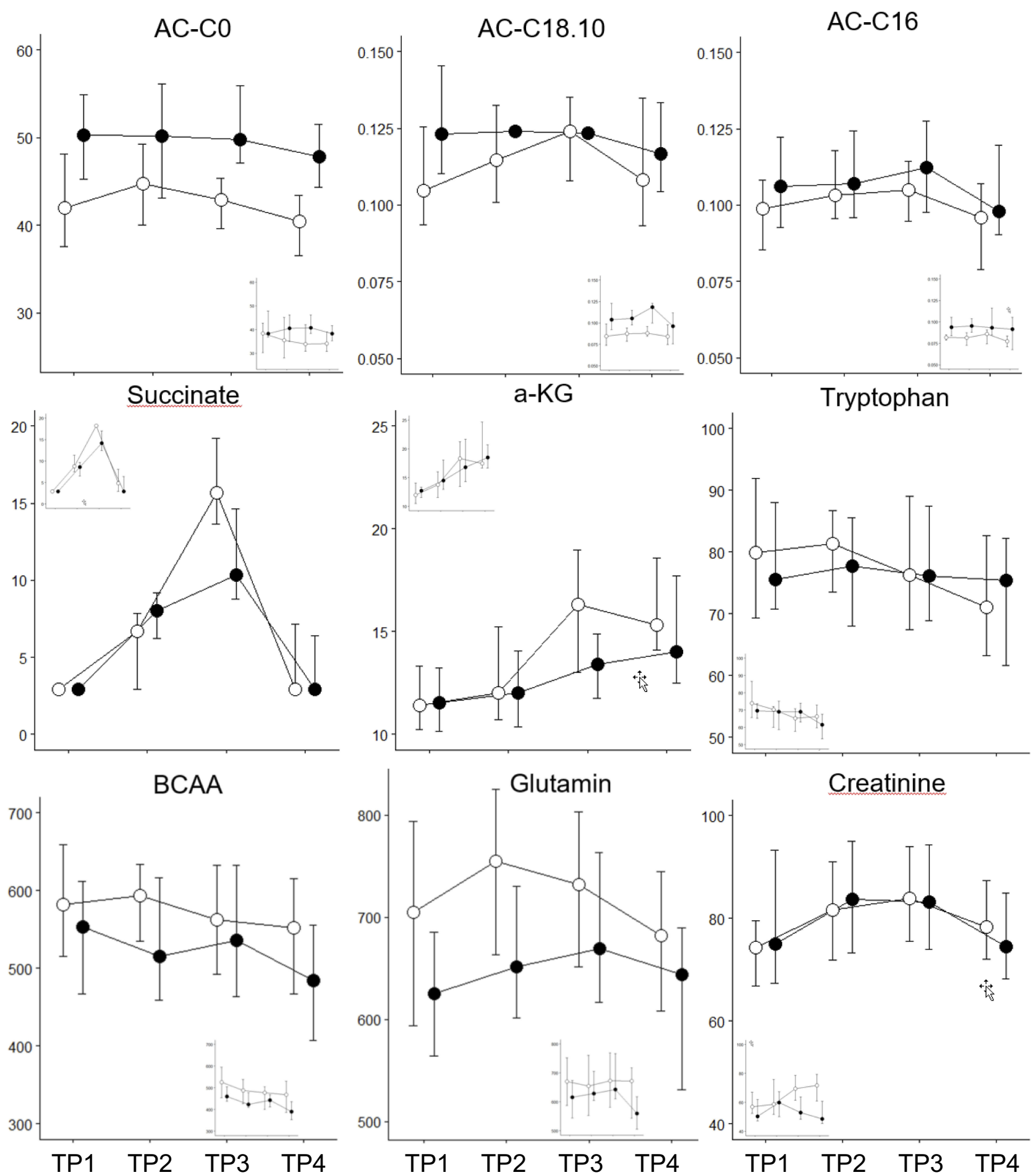

Figure 4 Metabolomic markers, which show significant differences between genders (major figure: male $n=17$, small inset: female $n=6$ ). Horizontal axis: the four time points, vertical axis: concentration in $\mu \mathrm{M}$ ) separately for smokers with (black) and without (white) COPD. Median and IQR, including the data of both exercise challenges.

acids in blood. ${ }^{27}$ Higher GLU concentrations ${ }^{28}$ as well as increased levels of ASP in COPD are in line with the increased use of amino acids for energy generation and the need for more nitrogen removal through the urea cycle. ASP receives the nitrogen group when GLU is converted to $\alpha-K G$ by the aspartate transaminase (AST) which links the TCA cycle to the urea cycle (Figure 5). GLU plays a major role in supplying the TCA cycle with "fuel" $(\alpha$ $K G)$. The increased GLU at rest in COPD did not lead to group differences in serum $\alpha-K G$ levels, but we saw 
Free Fatty Acids
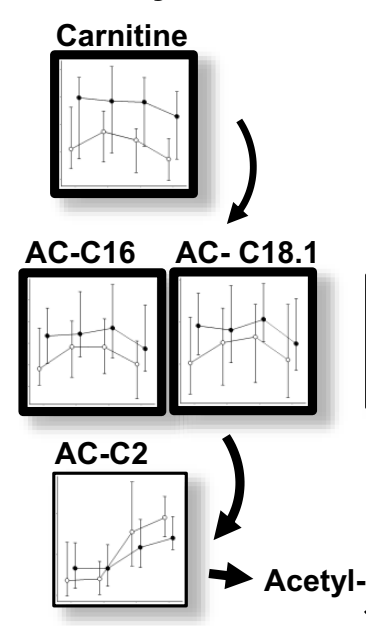

Carbohydrates

Proteins
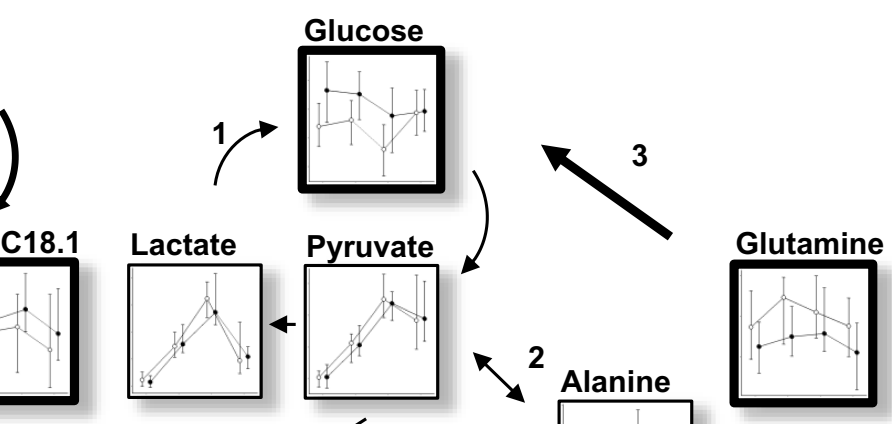

Alanine
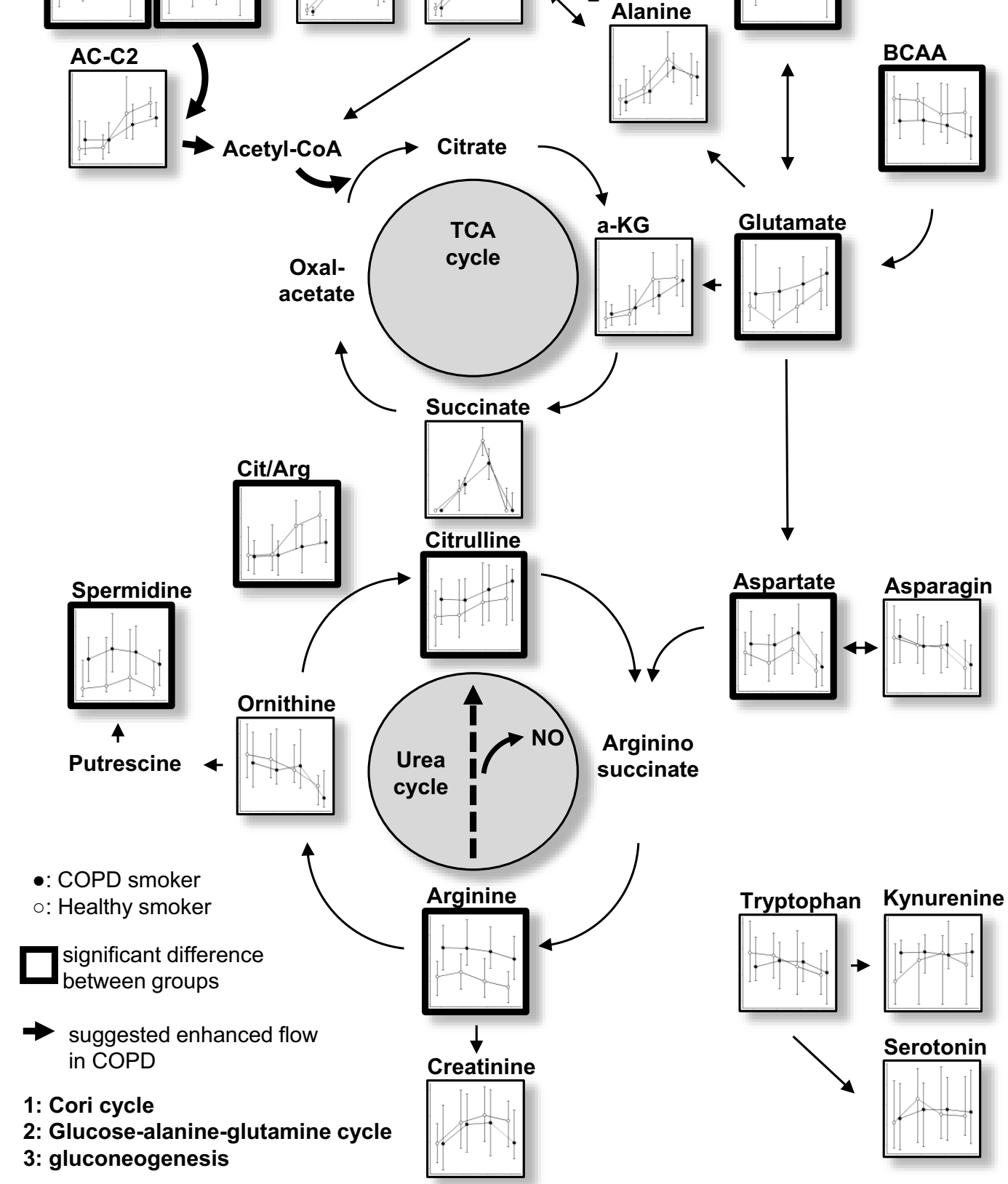

Figure 5 Overview of the analyzed metabolites and major pathways involved in energy metabolism, TCA cycle and urea cycle. Each small figure represents the median data for both groups and time points. Tryptophan and its metabolites are depicted on the bottom right. 
a weak correlation between GLU and $\alpha-K G$ at rest in COPD. A positive association of GLU to BCAA was also only seen in COPD at rest. In healthy smokers, the predominant associations of GLU were the amino acids involved in the urea cycle, especially ARG. Increased GLU concentrations in COPD at rest are not reported by others, ${ }^{12,14}$ perhaps due to differences in study designs.

\section{Amino Acids During Exercise}

There is also an exercise-induced increase in hepatic gluconeogenesis and energy generation through the TCA cycle, ${ }^{29}$ where amino acid carbon is utilized. During exercise, some amino acids, especially LEU, ILE or total BCAA showed a pronounced decline in healthy smokers only. BCAA are used by muscle as an energy source. ${ }^{30}$ Deamination of BCAA is the major nitrogen source for the synthesis of ALA and GLN in post-absorptive humans. ${ }^{31}$ Differences in the decline during exercise between groups suggest that COPD muscle utilizes this energy resource to a lesser extent, despite the fact that there is an increased demand. The ALA pattern is comparable to pyruvate (ALA cycle) and is correlated with GLN potentially based on the glucose-ALA-GLN relationship outlined by. ${ }^{32}$

As described above the pattern of GLU appears to be differently influenced. The stronger drop of GLU at the beginning of exercise could be related to the increased metabolic flow through the TCA cycle in healthy smokers, which is clearly visible at the end of the exercise, showing increased $\alpha-K G$ and succinate in healthy smokers. The almost inverse pattern of GLN and GLU are compatible with glutaminolysis, the process by which GLN is converted to GLU and to $\alpha-\mathrm{KG}$ to fuel the TCA cycle. ${ }^{33}$

Succinate and $\alpha-K G$ increase during exercise and show lower levels in COPD at the end of the exercise. As there is no correlation between exercise duration and the level of both metabolites within each group (Figure E6), it is unlikely that this is due to a shorter exercise duration of COPD patients. Therefore, the lower levels at the end of exercise could be caused by a lower metabolic rate of the TCA cycle in COPD. Reasons for this could be mitochondrial dysfunction, which has been discussed to play a role in COPD, ${ }^{34}$ or a lower availability of oxygen at the end of exercise in COPD patients.

\section{Amino Acids Involved in Nitrogen Removal}

There are also distinct group differences in amino acids involved in nitrogen removal. In line with higher GLU and ASP levels, we also see higher levels of ARG in COPD.
ARG is derived from dietary intake protein breakdown and endogenous de novo synthesis, which contributes to about $10-15 \%$ of ARG production. ${ }^{35}$ CIT is a product of ORN and carbamylphosphate and shows a trend to higher levels in the COPD. This reaction is the rate-limiting step of the urea cycle. ${ }^{36}$ We saw higher levels of spermidine, a product of ORN that plays a role in the regulation of cell proliferation and nucleic acid synthesis. ${ }^{37,38}$

Previous studies report higher levels of ARG in muscles of COPD patients, but not in arterial blood. ${ }^{12,13}$ In stable patients with moderate-to-severe COPD, endogenous ARG and CIT production is upregulated but no difference in whole body NO production was detectable (ARG-to-CIT flux). ${ }^{39}$

It has to be kept in mind that ARG and other urea cycle amino acids are compartmentalized in various tissues, and that their intracellular pools do not rapidly equilibrate with extracellular pools and serum. ${ }^{40}$ This could explain the variability between ARG, ORN and CIT with respect to differences between groups at rest. In addition, there are a number of enzymes involved in mammalian ARG metabolism. ${ }^{35,41}$ A disrupted ARG homeostasis appears to play a central role in asthma or COPD,${ }^{26}$ therefore the observed differences between groups in the increase of the CIT/ARG ratio during exercise are interesting, but it is difficult to draw substantial conclusions.

\section{Carnitines}

Carnitine and acylcarnitines play a major role in the transport of fatty acids into mitochondria, a process involving a large number of proteins and enzymes. ${ }^{42}$ Both can be detected in serum and their levels are thought to reflect the flux through the fatty acid oxidation pathways. ${ }^{43}$ Increased carnitine levels in COPD at rest and during exercise indicate an attenuated lipid metabolism. This is also reflected by the patterns of the two major acylcarnitines (palmitoyl (C16)-, oleylcarnitine (C18:1)) (Figure 5). The end product of fatty acid oxidation is acetyl-CoA, which is either directly used for the generation of energy by the TCA cycle, or is converted to acetylcarnitine for transport out of the mitochondria. ${ }^{42}$ The level of acetylcarnitine (acylcarnitine $\mathrm{C} 2$ ) is similar in both groups at rest, but during exercise and recovery, there is a stronger increase in healthy smokers. This indicates a greater flux of acetylCoA into the TCA cycle in COPD and provides further evidence for a shift in energy metabolism in this group (Figure 5). 


\section{Potential Implications}

It is known that about half of the patients with chronic bronchitis or COPD exhibit metabolic syndrome. ${ }^{44}$ In our study, the COPD patients did not show any signs of clinical manifestations of metabolic syndrome. However, the observed differences in the metabolic pattern of COPD smokers appear to be compatible with characteristics of metabolic syndrome and insulin resistance: 1) there is a shift in energy metabolism from carbohydrates (glucose) to a larger utilization of amino acids and free fatty acids; 2) there is an impaired ability of muscle tissue to utilize available amino acids during exercise as relevant energy source; and 3) there is a reduced flow through the TCA cycle during exercise resulting in a reduced workload.

The most pronounced differences between groups were found for ARG and GLU, which are involved in the removal of nitrogen. Taking into account the CIT/ARG ratio, it is tempting to speculate that a difference in the generation of nitric oxide (NO) is involved in this process.

We also observed a significantly higher level of spermidine in COPD smokers. It interacts with nucleic acids, histones and proteins and therefore plays a role in cell proliferation and repair.

\section{Conclusion}

Taken together, the exercise challenge amplified differences in energy and nitrogen metabolism that might be an early indicator or even a potential diagnostic test for subclinical metabolic syndrome in COPD.

\section{Acknowledgement}

The authors would like to thank all volunteer subjects and patients for their participation, and the staff of the Clinical Airway Research Unit for conducting the study.

\section{Funding}

Fraunhofer has received a research grant for conducting the study from Nycomed GmbH. Nycomed employees participated in study design, and in data analysis (SR, CS). OH, DSD, JMH were supported by the German Center for Lung Research.

\section{Disclosure}

$\mathrm{OH}$ : no competing interest; DD: no competing interest; SR: employee of the sponsor of the study Nycomed during its conduct; TI: no competing interest; KW: reports grants from
Biocrates Life Sciences, during the conduct of the study, contract research revenues from Altana during the conduct of the study, is a shareholder of Biocrates Life Sciences and a patent WO2007003343 issued, a patent WO2008145385 issued, and a patent WO2010139341 issued; CS: employee of the sponsor of the study Nycomed during its conduct; JH: received grants from Nycomed during the conduct of the study, personal fees from Boehringer Ingelheim, grants from AstraZeneca $\mathrm{AB}$, grants from Novartis, grants from Janssen Pharmaceutica NV, grants from ALK, grants from Boehringer Ingelheim, grants from LETI, grants from GlaxoSmithKline, GSK, grants from Sanofi-Aventis, personal fees from Merck \& Co, Inc., personal fees from Novartis, grants from Astellas Pharma, grants from Allergopharma, outside the submitted work.

\section{References}

1. Rabe KF, Watz H. Chronic obstructive pulmonary disease. Lancet. 2017;389(10082):1931-1940. doi:10.1016/S0140-6736(17)31222-9

2. Agustí A, Edwards LD, Rennard SI, et al. Persistent systemic inflammation is associated with poor clinical outcomes in COPD: a novel phenotype. PLoS One. 2012;7(5):e37483. doi:10.1371/journal. pone.0037483

3. Sin DD, Hollander Z, DeMarco ML, McManus BM, Ng RT. Biomarker development for chronic obstructive pulmonary disease. from discovery to clinical implementation. Am J Respir Crit Care Med. 2015;192(10):1162-1170. doi:10.1164/rccm.201505-0871PP

4. Barnes PJ, Burney PGJ, Silverman EK, et al. Chronic obstructive pulmonary disease. Nat Rev Dis Primers. 2015;1:15076. doi:10.1038/ nrdp. 2015.76

5. Holz O, Roepcke S, Watz H, Tegtbur U, Lahu G, Hohlfeld JM Constant-load exercise decreases the serum concentration of myeloperoxidase in healthy smokers and smokers with COPD. Int J Chron Obstruct Pulmon Dis. 2015;10:1393-1402. doi:10.2147/COPD. S83269

6. Gan WQ, Man SFP, Senthilselvan A, Sin DD. Association between chronic obstructive pulmonary disease and systemic inflammation: a systematic review and a meta-analysis. Thorax. 2004;59 (7):574-580. doi:10.1136/thx.2003.019588

7. Hurst JR, Donaldson GC, Perera WR, et al. Use of plasma biomarkers at exacerbation of chronic obstructive pulmonary disease. Am $J$ Respir Crit Care Med. 2006;174(8):867-874. doi:10.1164/ rccm.200604-506OC

8. Broekhuizen R, Wouters EFM, Creutzberg EC, Schols AMWJ. Raised CRP levels mark metabolic and functional impairment in advanced COPD. Thorax. 2006;61(1):17-22. doi:10.1136/thx.2005.041996

9. Moy ML, Teylan M, Weston NA, Gagnon DR, Danilack VA, Garshick E. Daily step count is associated with plasma C-reactive protein and IL-6 in a US cohort with COPD. Chest. 2014;145 (3):542-550. doi:10.1378/chest.13-1052

10. Watz H, Waschki B, Boehme C, Claussen M, Meyer T, Magnussen H. Extrapulmonary effects of chronic obstructive pulmonary disease on physical activity: a cross-sectional study. Am J Respir Crit Care Med. 2008;177(7):743-751. doi:10.1164/ rccm.200707-10110C

11. Jammes Y, Steinberg JG, Ba A, Delliaux S, Brégeon F. Enhanced exercise-induced plasma cytokine response and oxidative stress in COPD patients depend on blood oxygenation. Clin Physiol Funct Imaging. 2008;28(3):182-188. doi:10.1111/j.1475-097X.2008.00795.x 
12. Pouw EM, Schols AM, Deutz NE, Wouters EF. Plasma and muscle amino acid levels in relation to resting energy expenditure and inflammation in stable chronic obstructive pulmonary disease. Am J Respir Crit Care Med. 1998;158(3):797-801. doi:10.1164/ ajrccm.158.3.9708097

13. Engelen MP, Wouters EF, Deutz NE, Does JD, Schols AM. Effects of exercise on amino acid metabolism in patients with chronic obstructive pulmonary disease. Am J Respir Crit Care Med. 2001;163 (4):859-864. doi:10.1164/ajrccm.163.4.2006137

14. Engelen MP, Wouters EF, Deutz NE, Menheere PP, Schols AM. Factors contributing to alterations in skeletal muscle and plasma amino acid profiles in patients with chronic obstructive pulmonary disease. Am J Clin Nutr. 2000;72(6):1480-1487. doi:10.1093/ajcn/ 72.6.1480

15. Chen Q, Deeb RS, Ma Y, Staudt MR, Crystal RG, Gross SS. Serum metabolite biomarkers discriminate healthy smokers from COPD smokers. PLoS One. 2015;10(12):e0143937. doi:10.1371/journal. pone. 0143937

16. Telenga ED, Hoffmann RF, Ruben $\mathrm{T}$, et al. Untargeted lipidomic analysis in chronic obstructive pulmonary disease. Uncovering sphingolipids. Am J Respir Crit Care Med. 2014;190(2):155-164. doi:10.1164/rccm.201312-2210OC

17. Röpcke S, Holz O, Lauer G, et al. Repeatability of and relationship between potential COPD biomarkers in bronchoalveolar lavage, bronchial biopsies, serum, and induced sputum. PLoS One. 2012;7 (10):e46207. doi:10.1371/journal.pone.0046207

18. Holz O, Waschki B, Roepcke S, et al. Potential prognostic value of biomarkers in lavage, sputum and serum in a five year clinical follow-up of smokers with and without COPD. BMC Pulm Med. 2014;14:30. doi:10.1186/1471-2466-14-30

19. O'Donnell DE, Lam M, Webb KA. Measurement of symptoms, lung hyperinflation, and endurance during exercise in chronic obstructive pulmonary disease. Am J Respir Crit Care Med. 1998;158(5 Pt 1):1557-1565. doi:10.1164/ajrccm.158.5.9804004

20. Gieger C, Geistlinger L, Altmaier E, et al. Genetics meets metabolomics: a genome-wide association study of metabolite profiles in human serum. PLoS Genet. 2008;4(11):e1000282. doi:10.1371/journal.pgen. 1000282

21. Ramsay SL, Stoeggl WM, Weinberger KM, Graber A, Guggenbichler W, inventor. Apparatus and method for analyzing a metabolite profile.

22. Benjamini Y, Hochberg Y. Controlling the false discovery rate: a practical and powerful approach to multiple testing. J R Statist Soc B. 1995;(57):289-300. doi:10.1111/j.2517-6161.1995.tb02031.x

23. Engelen MP, Deutz NE, Wouters EF, Schols AM. Enhanced levels of whole-body protein turnover in patients with chronic obstructive pulmonary disease. Am J Respir Crit Care Med. 2000;162(4 Pt 1):1488-1492. doi:10.1164/ajrccm.162.4.2002045

24. Kutsuzawa T, Shioya S, Kurita D, Haida M. Plasma branched-chain amino acid levels and muscle energy metabolism in patients with chronic obstructive pulmonary disease. Clin Nutr. 2009;28 (2):203-208. doi:10.1016/j.clnu.2009.01.019

25. Devlin JT, Brodsky I, Scrimgeour A, Fuller S, Bier DM. Amino acid metabolism after intense exercise. Am J Physiol. 1990;258(2 Pt 1): E249-E255. doi:10.1152/ajpendo.1990.258.2.E249

26. van den Berg MP, Meurs H, Gosens R. Targeting arginase and nitric oxide metabolism in chronic airway diseases and their co-morbidities. Curr Opin Pharmacol. 2018;40:126-133. doi:10.1016/j.coph.20 18.04 .010
27. Stumvoll M, Perriello G, Meyer C, Gerich J. Role of glutamine in human carbohydrate metabolism in kidney and other tissues. Kidney Int. 1999;55(3):778-792. doi:10.1046/j.1523-1755.1999.055003778.x

28. Assmann N, Finlay DK. Metabolic regulation of immune responses: therapeutic opportunities. J Clin Invest. 2016;126(6):2031-2039. doi:10.1172/JCI83005

29. Henriksson J. Effect of exercise on amino acid concentrations in skeletal muscle and plasma. J Exp Biol. 1991;160:149-165.

30. Mattick JSA, Kamisoglu K, Ierapetritou MG, Androulakis IP, Berthiaume F. Branched-chain amino acid supplementation: impact on signaling and relevance to critical illness. Wiley Interdiscip Rev Syst Biol Med. 2013;5(4):449-460. doi:10.1002/wsbm.1219

31. Adeva MM, Calviño J, Souto G, Donapetry C. Insulin resistance and the metabolism of branched-chain amino acids in humans. Amino Acids. 2012;43(1):171-181. doi:10.1007/s00726-011-1088-7

32. Young VR, Ajami AM. Glutamine: the emperor or his clothes? J Nutr. 2001;131(9Suppl):2449S-59S; discussion 2486S-7S. doi:10.10 93/jn/131.9.2449S

33. Gaber T, Strehl C, Buttgereit F. Metabolic regulation of inflammation. Nat Rev Rheumatol. 2017;13(5):267-279. doi:10.10 38/nrrheum.2017.37

34. Meyer A, Zoll J, Charles AL, et al. Skeletal muscle mitochondrial dysfunction during chronic obstructive pulmonary disease: central actor and therapeutic target. Exp Physiol. 2013;98(6):1063-1078. doi:10.1113/expphysiol.2012.069468

35. Luiking YC, Have GAM, Wolfe RR, Deutz NEP. Arginine de novo and nitric oxide production in disease states. Am J Physiol Endocrinol Metab. 2012;303(10):E1177-E1189. doi:10.1152/ajpendo.00284.2012

36. Summar ML, Gainer JV, Pretorius M, et al. Relationship between carbamoyl-phosphate synthetase genotype and systemic vascular function. Hypertension. 2004;43(2):186-191. doi:10.1161/01.HYP.00 00112424.06921 .52

37. Ghisalberti CA, Borzì RM, Cetrullo S, Flamigni F, Cairo G. Soft TCPTP agonism-novel target to rescue airway epithelial integrity by exogenous spermidine. Front Pharmacol. 2016;7:147. doi:10.3389/ fphar.2016.00147

38. Handa AK, Fatima T, Mattoo AK. Polyamines: bio-molecules with diverse functions in plant and human health and disease. Front Chem. 2018;6:10. doi:10.3389/fchem.2018.00010

39. Jonker R, Deutz NE, Erbland ML, Anderson PJ, Engelen MP. Alterations in whole-body arginine metabolism in chronic obstructive pulmonary disease. Am J Clin Nutr. 2016;103(6):1458-1464. doi:10.3945/ajen.115.125187

40. Xu W, Ghosh S, Comhair SAA, et al. Increased mitochondrial arginine metabolism supports bioenergetics in asthma. J Clin Invest. 2016;126(7):2465-2481. doi:10.1172/JCI82925

41. Morris SM Jr. Recent advances in arginine metabolism: roles and regulation of the arginases. Br J Pharmacol. 2009;157(6):922-930. doi:10.1111/j.1476-5381.2009.00278.x

42. Christie WW. Carnitine, acylcarnitines and beta-oxidation. Available from: http://www.lipidhome.co.uk/lipids/simple/carnitin/index.htm. Updated March 10, 2018. Accessed May 23, 2018.

43. Schooneman MG, Vaz FM, Houten SM, Soeters MR. Acylcarnitines: reflecting or inflicting insulin resistance? Diabetes. 2013;62(1):1-8. doi: $10.2337 / \mathrm{db} 12-0466$

44. Watz H, Waschki B, Kirsten A, et al. The metabolic syndrome in patients with chronic bronchitis and COPD: frequency and associated consequences for systemic inflammation and physical inactivity. Chest. 2009;136(4):1039-1046. doi:10.1378/chest.09-0393 


\section{Publish your work in this journal}

The International Journal of COPD is an international, peer-reviewed journal of therapeutics and pharmacology focusing on concise rapid reporting of clinical studies and reviews in COPD. Special focus is given to the pathophysiological processes underlying the disease, intervention programs, patient focused education, and self management

protocols. This journal is indexed on PubMed Central, MedLine and CAS. The manuscript management system is completely online and includes a very quick and fair peer-review system, which is all easy to use. Visit http://www.dovepress.com/testimonials.php to read real quotes from published authors.

Submit your manuscript here: https://www.dovepress.com/international-journal-of-chronic-obstructive-pulmonary-disease-journal 